\title{
Polymorphism and Distribution of Ace Gene Involved in the Resistance of Musca Domestica to Organophosphates in Guizhou Province of China
}

\section{Rong Mou}

Guizhou Medical University

Xi Yang

Qiannan Medical College for Nationalities

Qiuguo Liang

Qiannan Medical College for Nationalities

Jinzhi Cheng

Guizhou Medical University

Yuanming Wu

Guizhou Medical University

\section{Gang Wang}

Zhejiang International Travel Healthcare Centre

Weilong Tan

Huadong Research Center for Medicine and biotechnics

Jia Hong Wu ( $\nabla_{\text {jiahongw@gmc.edu.cn ) }}$

Characteristic Lavoratory of Modern Pathogen Biology, Basic Medical Science College, Guizhou Medical University

\section{Research}

Keywords: Musca domestica, OPs resistance, acetylcholinesterase gene, mutation

Posted Date: June 14th, 2021

DOI: https://doi.org/10.21203/rs.3.rs-577578/v1

License: @) (7) This work is licensed under a Creative Commons Attribution 4.0 International License. Read Full License 


\section{Abstract}

Acetylcholinesterase is the primary target of organophosphates (OPs) and carbamates in insects. As gene mutation has been verified as an important mechanism of insecticide resistance in insects, in this study, we investigated the status of OPs resistance and the polymorphism of ace gene (that encodes acetylcholinesterase) in housefly (Musca domestica $L$ ) field populations in Guizhou Province, China. Bioassays showed that the houseflies had 142.16303.54-fold resistance to dichlorvos (DDVP) and 122.13-363.98-fold resistance to temephos. Molecular analysis revealed resistance-causing mutations of ace gene at loci of 260,342 and 407 in the housefly populations, with a total frequency of $55 \%, 100 \%$ and $94 \%$, respectively. In addition, 11 combinations of a ce mutation were observed across the detected populations. The most frequently detected combination was $L / V+A / V+Y$, followed by $L+A+Y$ and $L / V+A+Y$. No significant relationship was found between single mutation/combination mutations and DDVP resistance. These results indicate that the OPs resistance is prevalent among the housefly populations in Guizhou Province, with a similar pattern of allele mutation of ace across China. The target resistance can not fully account for the resistance of houseflies to OPs in Guizhou.

\section{Introduction}

Houseflies, Musca domestica, are a transmission vector of more than 100 human and animal pathogens, including bacteria, parasites, viruses, and rickettsia[1]. Until now, chemicals with strong insect lethality have been widely used to control houseflies. Currently, the use of harmful insecticides has amounted to 1.8 billion kilograms in China and the amount of hazardous insecticide use in the USA has reached 31.75 million kilograms in urban settings[2, 3]. Although the chemical insecticides can effectively control houseflies and the diseases they carry, the long-term, extensive use of insecticides can lead to the development of insecticide resistance in houseflies[4, 5]. A study in 48 Chinese cities has suggested that the houseflies have developed a strong resistance to several common insecticides, such as dichlorvos (DDVP), temephos and deltamethrin[6]. This indicates that the resistance to organophosphate (OP) insecticides including DDVP and temephos has become a serious concern in the control of local houseflies in China.

It has been revealed that the resistance of houseflies to OPs is mainly attributed to the insensitive target-site acetylcholinesterase $(\mathrm{AChE})[3,7,8]$. $\mathrm{AChE}(\mathrm{EC}$ 3.1.1.7), encoded by the ace gene, is the key enzyme of the cholinergic system in insects[9]. OPs and carbamates (CBs) can irreversibly bind with AChE and cause phosphorylation or carbamylation of the enzyme at the active serine site, leading to the accumulation of acetylcholine at synapses[10, 11]. This in turn leaves the acetylcholine receptor permanently open, resulting in the death of the insect[10]. However, modification or mutation of the ace gene can change the structure of AChE, thereby reducing or eliminating the binding affinity of insecticides at the target-site and inducing the resistance to OPs and CBs[8, 12, 13]. For houseflies, there is only a single ace gene in the whole genome[14]. Currently, six mutations (V260L, A316S,G342A/V, F407Y and G445A) have been verified to be present separately or in combination within a particular active site of AChE that can change the current of the catalytic triad and restrict the bind ability to insecticides, thus being responsible for the development of resistance $[8,15,16]$.

In Guizhou Province located in the southwest part of China, the insecticide resistance of houseflies has been reported only by one study (1999) [17]. With the campaign of establishing the national sanitary cities across China, the resistance of houseflies to propoxur and DDVP has been reported in some major cities of Guizhou, such as Anshun, Guiyang and Xingyi, in recently years[18-20]. However, little is known about the underlying genetic variability of AChE that confers the resistance to OPs and CBs. In this study, we set out to explore the resistance status of houseflies to OPs and investigate the genetic mutations of ace in the housefly (Musca domestica $L$ ) field populations across Guizhou Province.

\section{Materials And Methods}

\section{Collection and rearing of houseflies}

The housefly observation, adult housefly collection, and field studies in Guizhou Province were conducted from April 2018 to December 2019 . Adult $M$. domestica houseflies were collected in urban or suburban areas distributed in 7 different regions in Guizhou Province (Fig. 1). In the current study, about 100 houseflies were collected by the sweep net mainly in waste transfer stations and refused dump of the farmer markets or old residential buildings, and then mixed to represent a local population. All of the field-collected populations were routinely reared with a mixture of milk powder and granulated sugar at a ratio of $1: 1$ in an appropriate amount of water, at a constant indoor temperature of $25 \pm 1{ }^{\circ} \mathrm{C}$, with humidity of $70 \pm 10 \%$ under a $12 \mathrm{~h}$ light/ $12 \mathrm{~h}$ dark cycle. Housefly eggs were laid in wheat bran $(100 \mathrm{~g})$, with milk powder $(5 \mathrm{~g})$, granulated sugar $(5 \mathrm{~g})$ and water $(130 \mathrm{~mL})$, as the random mating of houseflies occurred in the breeding cage. The eggs were hatched to pupate on the dry surface of the feed within 7 days. The adult susceptibility bioassay and molecular tests were conducted using the first-generation, field-collected houseflies of 3-5 days old with a similar body weight of 18-22 mg.

\section{Bioassays}

Bioassays were performed in accordance with the Bioassay Methods for Musca domestica (GB/T 26350 (2010)) released by the Standardization Administration of the People's Republic of China[21]

The 97.6\% DDVP and 87.4\% temephos solutions provided by the Chinese Center for Disease Control and Prevention (CDC) were first dissolved in acetone and then half-diluted to a series of concentrations. The customized $0.35 \mu \mathrm{L}$ pippets purchased from Nanjing Agricultural University (Nanjing, China) were used to conduct bioassays for each housefly population. The assays at each concentration of DDVP and temephos were performed in three replicates, with acetone being used as a negative control. The regression equations were obtained using the mortality $24 \mathrm{~h}$ after drug exposure in each test recorded after. The $\mathrm{LD}_{50}$ (lethal dose, $50 \%$ ) value was calculated based on the corresponding insecticide concentrations. The mortality of the control group was below $5 \%$. The resistance ratio (RR) was obtained from dividing the $\mathrm{LD}_{50}$ of different populations by the $\mathrm{LD}_{50}$ of the susceptible housefly. 


\section{Extraction of genomic DNA}

The genomic DNA of houseflies was extracted according to the description by Yang et al.[20]. A whole adult housefly was homogenized in $300 \mu \mathrm{L}$ extraction buffer in a $1.5 \mathrm{~mL}$ Eppendorf tube, and proteinase $\mathrm{K}(50 \mu \mathrm{g})$ was added. The homogenates were incubated at $56^{\circ} \mathrm{C}$ overnight. Then a solution $(300 \mu \mathrm{L})$ of chloroform and isoamyl alcohol (24:1) was added. After shaking violently for several times, the samples were centrifuged at $10000 \mathrm{rpm} / \mathrm{min}$ at $4{ }^{\circ} \mathrm{C}$ for 10 min. The supernatant was transferred to a new tube, and a 0.1 -fold volume of $3 \mathrm{M}$ sodium acetate $\left(4^{\circ} \mathrm{C}\right)$ and a 2 -fold volume of pure ethanol were added to precipitate DNA for $2 \mathrm{~h}$. Afterwards, the supernatant was discarded after centrifugation at $12000 \mathrm{rpm} / \mathrm{min}$ for 5 min at $4{ }^{\circ} \mathrm{C}$, and the DNA was washed twice with $70 \%$ ethanol $(1 \mathrm{~mL})$. Finally, the DNA was resolved with $\mathrm{ddH}_{2} \mathrm{O}$ and stored at $-20^{\circ} \mathrm{C}$ until use.

\section{Amplification and sequencing of ace gene}

The ace gene fragment was amplified by PCR in a $25-\mu \mathrm{L}$ reaction system containing $12.5 \mu \mathrm{L}$ of Premix Taq ${ }^{\text {TM }}$ (TAKARA Bio Inc., Shiga, Japan), $8.5 \mu \mathrm{L}$ of $\mathrm{ddH}_{2} \mathrm{O}, 2 \mu \mathrm{L}$ of DNA template, and $1 \mu \mathrm{L}$ of each of $10 \mu \mathrm{M}$ forward primer S90MdAce (5'- CATCT AAAAC CGATC AGGAC CATTT AATAC-3') and $10 \mu \mathrm{M}$ reverse primer AS89MdAce (1 $\mu \mathrm{L})\left(5^{\prime}\right.$-TCATC TTTAA CATTT CCAAT CAGAA TATCG-3') [22]. PCR reactions were run in a SimpliAmp ${ }^{\text {TM }}$ Thermal Cycler (Thermo Fisher Scientific Inc., Waltham, MA, USA) under the following conditions: $94{ }^{\circ} \mathrm{C}$ for $3 \mathrm{~min}$, followed by 35 cycles of $95{ }^{\circ} \mathrm{C}$ for $30 \mathrm{~s}, 55^{\circ} \mathrm{C}$ for $30 \mathrm{~s}$, and $72^{\circ} \mathrm{C}$ for $90 \mathrm{~s}$, and a final extension at $72{ }^{\circ} \mathrm{C}$ for $10 \mathrm{~min}$ [16]. PCR products $(5 \mu \mathrm{L})$ were identified and bi-directionally sequenced by Majorbio Bio Tech Co., Ltd. (Shanghai, China). Homozygous and heterozygous individual houseflies were identified by manual inspection of the sequencing and chromatograms. .

\section{Statistical analysis}

The $\mathrm{LD}_{50}$ of insecticides in the tested populations was calculated with a probit analysis based on the recorded concentration-mortality data. Association between ace genotype and phenotypical resistance was analyzed with the Spearman's correlation coefficient. All analyses were conducted using SPSS 22.0 software (IBM, Armonk, NY, USA).

\section{Results}

\section{Resistance of housefly populations to insecticides}

The resistance of houseflies to DDVP and temephos was analyzed in 5 and 4 populations, respectively. The LD 50 values of DDVP and temephos ranged 0.56865-1.21415 $\mu \mathrm{g} /$ housefly and 13.8005-41.12605 $\mu \mathrm{g} /$ housefly, respectively. The two OPs showed a high resistance ratio, 122.13 363.95-fold for temephos and 142.16 303.54-fold for DDVP (Table 1).

\section{The distribution and frequency of ace mutations}

A total of 237 PCR products of ace gene were obtained and sequenced. Nonsynonymous mutations were detected only at the loci of V260, G342, and F407 among the field-collected populations (Fig. 2). The frequencies of these mutant alleles were $55 \%, 100 \%$, and $94 \%$ respectively. In addition, $23.63 \%$ and $4.24 \%$ of the houseflies were homozygous for L260 and V260 respectively, whereas $72.13 \%$ were heterozygous. Only 2 mutation genotypes (A/V or A/A) were detected at the locus 342 , and the frequencies were $63.94 \%$ and $36.06 \%$, respectively. At the locus 407 , three genotypes (F/F®F/Y and $Y / Y)$ were found and $91.7 \%$ of the houseflies were homozygotes for $\mathrm{Y} / \mathrm{Y}$ (Table 2). The KL and GY were two top populations for the simultaneous mutation frequency of the three loci, while the $\mathrm{CH}$ and $\mathrm{ZY}$ populations had the lowest simultaneous mutation frequency of the three loci.

Eleven combinations of ace mutation were detected among the populations (Fig. 3). The combination of L/V+A/V+Y had the highest frequency (59.9\%), followed by the $L+A+Y(22.8 \%)$ and $L / V+A+Y(8 \%)$. The $Z Y$ population had seven combinations, the AS population had five combinations, the LPS, HS and GY populations each had four combinations, and the CS population had the least 2 combinations. No distinct differences among the populations had been found.

\section{Relationship between ace mutation and insecticide resistance}

According to the bioassay results of DDVP in 5 field populations, we conducted the correlation analysis to explore the relationship between single or combined mutations of ace gene and DDVP resistance phenotype (Fig.4). However, no significant correlation was detected between them.

\section{Discussion}

In China, OPs and CBs have been widely used in the public health field since 1950s, because of the low costs and high efficiency[23]. The development of insecticide resistance during housefly control has been widely reported in China. Previous studies on houseflies collected from Xingyi City and Anshun City in Guizhou have also shown a high resistance to OPs and CBs[18-20]. The current bioassay results further revealed the presence of a high resistance to OPs in houseflies in Guizhou Province.

The ace gene of housefly has been demonstrated as an indicator for the response to OPs and CBs stress[22]. In this study, 6 alleles at loci 260,342 , and 407 were detected in all 7 housefly populations in Guizhou Province. It is noteworthy that the frequency of allele mutation was $100 \%$ at locus 342 and $94 \%$ at locus 407. This is consistent with previous report on ace gene in houseflies in Guangdong and Shanghai, China[24]. Previous studies have shown that both G342A/V and F407Y mutations, which are located close to the active-site triad of AChE at the base of the gorge, can cause resistance to OPs and CBs, with G342A/V mutation likely to affect the orientation of the catalytic serine and F407Y decreasing the available space within the acyl-binding pocket[8].

Page $3 / 9$ 
Meanwhile, the $342 \mathrm{~V}$ mutation has a much more significant effect on the properties of AChE than $342 \mathrm{~A}$, which causes a $>10$-fold decrease in substrate affinity compared to the wild-type enzyme[8,25]. In the present study, the frequency of the 342A/V genotype (61.9\%) was higher than that of the 342A/A genotype $(36.1 \%)$, which might suggest that the 342A/V genotype confers higher resistance to OPs. Interestingly, $342 \mathrm{~V}$ homozygotes have not been detected in the present or previous studies, either in China or in other countries outside of China[16,22,24].It is further suggested that houseflies with the $342 \mathrm{~V}$ mutation carry higher fitness cost[24,26]. For mutations at the locus 407, 407Y conferred 1.8-fold resistance to DDVP[8], and the genotype 407Y/Y (91.7\%) ranked top in frequency among three genotypes in all detected populations. Similar results have been found in other places in China[24].

It has been found that combined mutations of ace often confer higher resistance than single mutations[8,25]. Here, 11 combinations of three mutations (V260L, G342A/V, and F407Y) were observed in the field populations. Houseflies with any of these combinations showed resistance to OPs and CBs. $V / L+A / V+Y$ and $L+A+Y$ were the top 2 combinations in frequency, which caused 48-fold resistance to DDVP compared to the wild-type[8]. This mutation pattern of ace has also been found in other regions of China [24], and in Japan, Turkey[22] and Europe[25], but not in the USA[16], which indicates that the resistance alleles vary globally in different regions. The combination $V / L+A+Y$ has been detected in Guangdong Province in south of China, but not in Shanghai, Shandong, Beijing, or Jilin, which are located in east and north of China[24]. In the present study, the combination $V / L+A+Y$ was found in the housefly populations, and also ranked third in frequency. This suggests that this pattern of mutation is common in south China.

There was no distinct distribution division of ace resistance alleles either for single mutation or combined mutations, among the different field populations in Guizhou. This might be the result of two evolutionary forces (mutation and migration). The allelic diversity in field populations might enable them survive against the different insecticides[27]. Correspondingly, application of a multiplicity of treatments on field populations might result in the population heterogeneity, composed of a mixture of different alleles.

Although the current study showed a high resistance phenotype, no significant relationship was found between either single mutation or combined mutations and DDVP resistance. This indicates that target resistance is not the only mechanism involved in the housefly resistance to OPs in Guizhou. Further studies are needed to clarify the resistance mechanism.

\section{Conclusion}

In conclusion, the resistance to OPs exists widely in houseflies in Guizhou Province. A similar pattern of allele mutation of ace has been found across China. The findings imply a need for monitoring on insecticide use to avoid the abuse of insecticides. It also demonstrates that target resistance is not enough to account for housefly resistance to OPs in Guizhou.

\section{Declarations}

\section{Acknowledgments}

We would like to thank Prof. Fengxia Meng from the Chinese Center for Disease Control and Prevention (CDC) for her kindly providing the insecticides used in this study. We also thank the anonymous reviewers who provided constructive suggestions.

\section{Funding}

This work was supported by the Science and Technology Planning Project of Guiyang (No. [2012103]28), the Project of Basic Science and Technology Platform in Guizhou Province, China (No. 2012[4006]) and Opening Project of Key Laboratory of Ministry of Education for Environmental Pollution and Disease Monitoring (GMU2016-HJZ-05).The funders had no role in study design, data collection and analysis, decision to publish, or preparation of the manuscript.

\section{Authors' Contribution}

WJH and TWL designed the whole study, genetic analysis and wrote the manuscript. MR and YX performed housefly collection, bioassay and genotyping. LQG and WYM performed housefly collection and data processing. CJZ performed data processing and genetic analysis. WG provided technical support in equipment use. All authors read and approved the final manuscript.

\section{Corresponding author}

Corresponding to Jiahong Wu and Weilong Tan.

\section{Ethics approval and participant consent}

All the field studies on housefly were approved by the Institutional Animal Care and Use Committee of Guizhou Medical University (China).

\section{Consent for publication}

No applicable.

\section{Availability of data and material}

No. 


\section{Competing interests}

The authors declare that they have no competing interests.

\section{References}

1. Khamesipour F, Lankarani KB, Honarvar B, Kwenti TE. A systematic review of human pathogens carried by the housefly (Musca domestica L.). BMC Public Health. 2018;18:1049.

2. Chen XM, Wang CL, Bo R. Current situation of chinese pesticide application and policy suggestions. Pesticide Sci Admini. 2016;37:4-8.

3. Zhu F, Lavine L, O Neal S, Lavine M, Foss C, Walsh D. Insecticide resistance and management strategies in urban ecosystems. Insects. 2016;7:2.

4. Liu N, Yue X. Insecticide resistance and cross-resistance in the house fly (Diptera: Muscidae). J Econ Entomol. 2000;93:1269-75.

5. Scott JG. Evolution of resistance to pyrethroid insecticides in Musca domestica. Pest Manag Sci. 2017;73:716-22.

6. Huang Z, Xian J, Hu J, Ye G, Yang D, Liu Y, Zeng H. Resistance of Musca domestica to commonly used insecticides in China. Chin J Hyg Insect Equip. 2015;21:306-8.

7. Kozaki T, Tomita T, Taniai K, Yamakawa M, Kono Y. Expression of two acetylcholinesterase genes from organophosphate sensitive-and insensitivehouseflies, Musca domestica L. (Diptera: Muscidae), using a baculovirus insect cell system. Appl Entomol Zool. 2002;37:213-8.

8. Walsh SB, Dolden TA, Moores GD, Kristensen M, Lewis T, Devonshire AL, Williamson MS. Identification and characterization of mutations in housefly (Musca domestica) acetylcholinesterase involved in insecticide resistance. Biochem J. 2001;359:175-81.

9. Huchard E, Martinez M, Alout H, Douzery EJ, Lutfalla G, Berthomieu A, Berticat C, Raymond M, Weill M. Acetylcholinesterase genes within the Diptera: Takeover and loss in true flies. Proc Biol Sci. 2006;273:2595-604.

10. Casida JE, Durkin KA. Neuroactive insecticides: Targets, selectivity, resistance, and secondary effects. Annu Rev Entomol. 2013;58:99-117.

11. Liu N. Insecticide resistance in mosquitoes: Impact, mechanisms, and research directions. Annu Rev Entomol. 2015;60:537-59.

12. Kozaki T, Shono T, Tomita T, Kono Y. Fenitroxon insensitive acetylcholinesterases of the housefly, Musca domestica associated with point mutations. Insect Biochem Mol Biol. 2001;31:991-7.

13. You C, Shan C, Xin J, Li J, Ma Z, Zhang Y, Zeng X, Gao X. Propoxur resistance associated with insensitivity of acetylcholinesterase (AChE) in the housefly, Musca domestica (Diptera: Muscidae). Sci Rep. 2020;10:8400.

14. Scott JG, Warren WC, Beukeboom LW, Bopp D, Clark AG, Giers SD, Hediger M, Jones AK, Kasai S, Leichter CA, Li M, Meisel RP, Minx P, Murphy TD, Nelson DR, Reid WR, Rinkevich FD, Robertson HM, Sackton TB, Sattelle DB, Thibaud-Nissen F, Tomlinson C, van de Zande L, Walden KK, Wilson RK, Liu N. Genome of the house fly, Musca domestica L., A global vector of diseases with adaptations to a septic environment. Genome Biol. 2014;15:466.

15. Kim CS, Kim WT, Boo KS, Kim SI. Cloning, mutagenesis, and expression of the acetylcholinesterase gene from a strain of Musca domestica; The change from a drug-resistant to a sensitive enzyme. Mol Cells. 2003;15:208-15.

16. Kozaki T, Brady SG, Scott JG. Frequencies and evolution of organophosphate insensitive acetylcholinesterase alleles in laboratory and field populations of the house fly, Musca domestica L. Pestic Biochem Phys. 2009;95:6-11.

17. Lin M, Zhu X. Resistance Investigation of Musca domestica to 4 insecticides in Guiyang City. J Med Pest Control 1999:263-264.

18. Liang W, Tian Z, Yang X, Liu Z, Zhou Z. Insecticide resistance of Musca domestica in Xingyi City. Chin J Hyg Insect Equip. 2016;22:349-50.

19. Liang W, Xie P, Dai H, Li H, Tian Z, Liu Z, Zou Z. Resistance of Musca domestica to commonly used insecticides in Anshun city, Guizhou province. Chin J Vector Biol Control. 2017;28:362-3.

20. Yang X, Zhang L, Yang X, Cheng J, Wu Y, Liu J, Wu J. Relationship between kdr(L1014F) allele and pyrethroid resistance of housefly in Guiyang. Acta Parasit Med Entom Sin. 2016;23:218-23.

21. China NHAF. Test methods of fly resistance to insecticides-The bioassay methods for Musca domestica. Edited by Standard TPSR; 2011.

22. Baskurt S, Taskin BG, Dogac E, Taskin V. Polymorphism in the acetylcholinesterase gene of Musca domestica L. Field populations in Turkey. J Vector Ecol. 2011;36:248-57.

23. Leng PE. Insecticides and control technology used for flies control in China. Chin J Hyg Insect Equip. 2012;18:269-73.

24. Wang Q, Li M, Pan J, Di M, Liu Q, Meng F, Scott JG, Qiu X. Diversity and frequencies of genetic mutations involved in insecticide resistance in field populations of the housefly (Musca domestica L.) from China. Pestic Biochem Phys. 2012;102:153-9.

25. Kristensen M, Huang J, Qiao CL, Jespersen JB. Variation of Musca domestica L. acetylcholinesterase in Danish housefly populations. Pest Manag Sci. 2006;62:738-45.

26. Shi MA, Lougarre A, Alies C, Fremaux I, Tang ZH, Stojan J, Fournier D. Acetylcholinesterase alterations reveal the fitness cost of mutations conferring insecticide resistance. BMC Evol Biol. 2004;4:5.

27. Menozzi P, Shi MA, Lougarre A, Tang ZH, Fournier D. Mutations of acetylcholinesterase which confer insecticide resistance in Drosophila melanogaster populations. BMC Evol Biol. 2004;4:4.

\section{Tables}

Tab. 1 Organophosphates resistance of the field-collected houseflies in Guizhou Province 


\begin{tabular}{|llllll|}
\hline Insecticide & Population & $\mathrm{n}$ & $\mathrm{LD}_{50} \& 95 \% \mathrm{Cl}(\mu \mathrm{g} /$ housefly $)$ & Slope & $\mathrm{RR}$ \\
\hline DDVP & $\mathrm{AS}$ & 450 & $0.7231(0.6468 \sim 0.8071)$ & 2.56 & 180.78 \\
& $\mathrm{GY}$ & 450 & $1.21415(0.90335 \sim 1.6856)$ & 2.621 & 303.54 \\
& $\mathrm{HS}$ & 450 & $0.56865(0.52115 \sim 0.69685)$ & 3.538 & 142.16 \\
& $\mathrm{KL}$ & 450 & $0.72205(0.6538 \sim 0.79625)$ & 2.58 & 180.51 \\
\hline ZY & 450 & $0.63315(0.55825 \sim 0.721)$ & 3.712 & 158.29 \\
\hline Temephos & Susceptible & - & $0.004(0.003 \sim 0.005)$ & 1.052 & 1 \\
\hline & GY & 450 & $24.01385(11.1251 \sim 35.161)$ & 2.16 & 212.51 \\
\hline & 450 & $17.26095(11.1251 \sim 26.95385)$ & 2.356 & 152.75 \\
\hline HS & 450 & $13.8005(11.64275 \sim 17.2522)$ & 1.858 & 122.13 \\
\hline & KL & 450 & $41.12605(33.2248 \sim 54.005)$ & 1.326 & 363.95 \\
\hline
\end{tabular}

Tab. 2 Distribution, polymorphisms and mutation frequencies of ace alleles and genotypes at locus 260, 342 and 402 in houseflies in Guizhou province, China

\begin{tabular}{|c|c|c|c|c|c|c|c|c|c|c|c|c|c|c|}
\hline \multirow[t]{3}{*}{ Population } & \multirow[t]{3}{*}{$\mathrm{n}$} & \multicolumn{8}{|c|}{ Loci and Genotype Frequency \% } & \multicolumn{4}{|c|}{ Mutation Allele Frequency \% } & \multirow{3}{*}{$\begin{array}{l}\text { Simultaneous } \\
\text { Mutation } \\
\text { Frequency } \\
\text { of the Three } \\
\text { Loci \% }\end{array}$} \\
\hline & & \multicolumn{3}{|l|}{260} & \multicolumn{2}{|l|}{342} & \multicolumn{3}{|l|}{407} & \multirow{2}{*}{$\begin{array}{l}260 \\
\mathrm{~L}\end{array}$} & \multicolumn{2}{|l|}{342} & \multirow{2}{*}{$\begin{array}{l}407 \\
\mathrm{Y}\end{array}$} & \\
\hline & & $\mathrm{L} / \mathrm{V}$ & $\mathrm{L} / \mathrm{L}$ & $\mathrm{V} / \mathrm{V}$ & $\mathrm{A} / \mathrm{V}$ & $A / A$ & $F / Y$ & $Y / Y$ & $\mathrm{~F} / \mathrm{F}$ & & A & V & & \\
\hline AS & 31 & 77.4 & 12.9 & 9.7 & 71.0 & 29.0 & 0 & 90.3 & 9.7 & 51.6 & 64.5 & 35.5 & 90.3 & 46.6 \\
\hline CS & 53 & 54.7 & 45.3 & 0 & 54.7 & 45.3 & 0 & 100.0 & 0 & 27.4 & 72.7 & 27.3 & 100.0 & 27.4 \\
\hline GY & 30 & 77.7 & 22.3 & 0 & 46.7 & 53.3 & 6.7 & 93.3 & 0 & 72.7 & 76.7 & 23.7 & 96.7 & 70.3 \\
\hline HS & 33 & 81.8 & 18.2 & 0 & 81.8 & 18.2 & 15.2 & 81.8 & 3 & 59.1 & 59.1 & 40.9 & 89.4 & 52.8 \\
\hline $\mathrm{KL}$ & 30 & 53.3 & 46.7 & 0 & 56.7 & 43.3 & 3.3 & 96.7 & 0 & 73.8 & 71.7 & 28.3 & 98.4 & 72.6 \\
\hline LPS & 30 & 93.3 & 6.7 & 0 & 70.0 & 30.0 & 0 & 100.0 & 0 & 53.4 & 65.0 & 35.0 & 100.0 & 53.4 \\
\hline ZY & 30 & 66.7 & 13.3 & 20 & 66.7 & 33.3 & 6.7 & 80.0 & 13.3 & 46.7 & 66.7 & 33.3 & 83.4 & 38.9 \\
\hline total & 237 & 72.13 & 23.63 & 4.24 & 63.94 & 36.06 & 4.56 & 91.69 & 3.71 & 55 & 68 & 32 & 94 & 51.7 \\
\hline
\end{tabular}

\section{Figures}




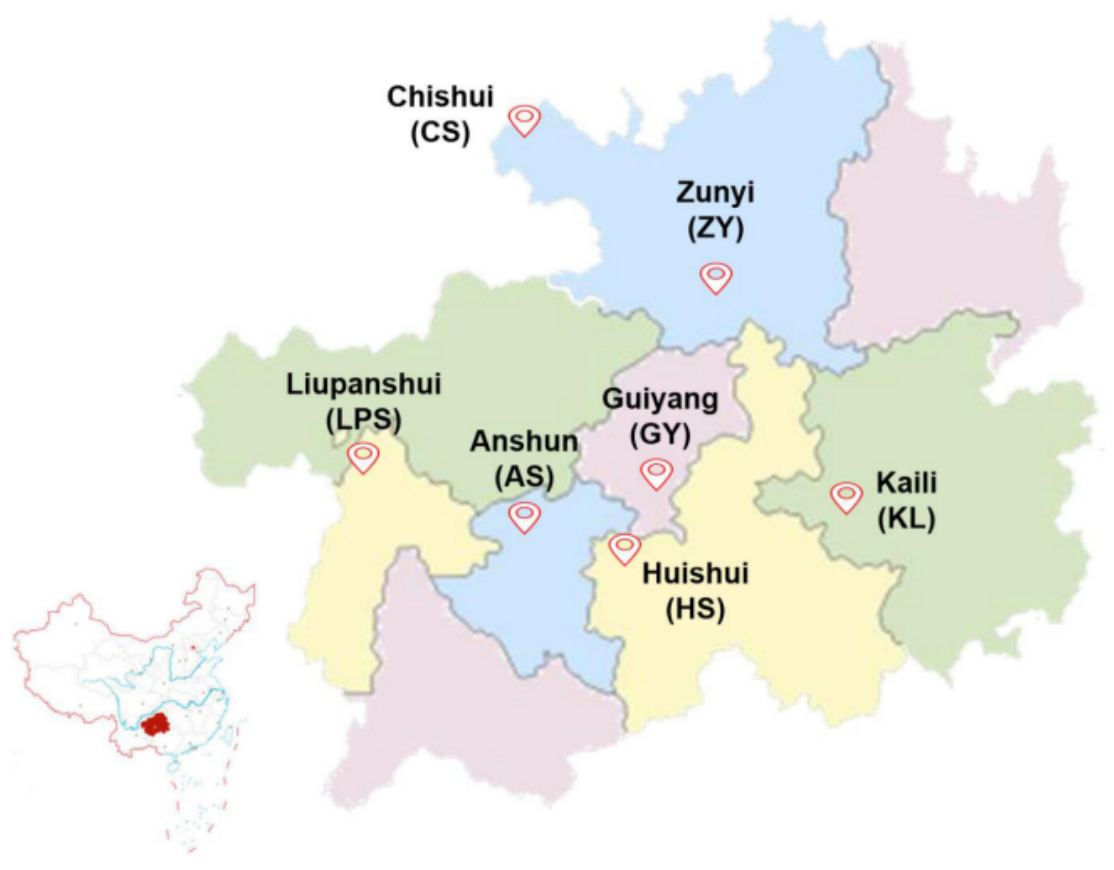

\section{Figure 1}

Sampling sites of field houseflies in Guizhou Province, China. Anshun (AS), $26^{\circ} 16^{\prime} \mathrm{N} 105^{\circ} 59^{\prime} \mathrm{E}$; Chishui (CS), $28^{\circ} 34^{\prime} \mathrm{N} 105^{\circ} 42^{\prime} \mathrm{E} ; \mathrm{Guilyang}(\mathrm{GY}), 26^{\circ} 38^{\prime} \mathrm{N} 106^{\circ} 47^{\prime} \mathrm{E}$; Huishui (HS), $26^{\circ} 07^{\prime} \mathrm{N} 106^{\circ} 39^{\prime} \mathrm{E}$; Kaili (KL), $26^{\circ} 35^{\prime} \mathrm{N} 107^{\circ} 58^{\prime} \mathrm{E}$; Liupanshui (LPS), $26^{\circ} 35^{\prime} \mathrm{N} 104^{\circ} 49^{\prime} \mathrm{E}$; Zunyi (ZY), $27^{\circ} 43^{\prime} \mathrm{N} 106^{\circ} 54^{\prime} \mathrm{E}$. Note: The designations employed and the presentation of the material on this map do not imply the expression of any opinion whatsoever on the part of Research Square concerning the legal status of any country, territory, city or area or of its authorities, or concerning the delimitation of its frontiers or boundaries. This map has been provided by the authors. 


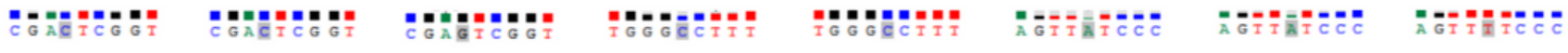

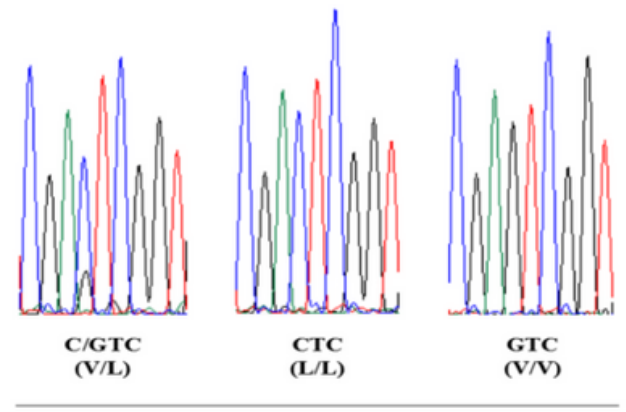

Locus 260

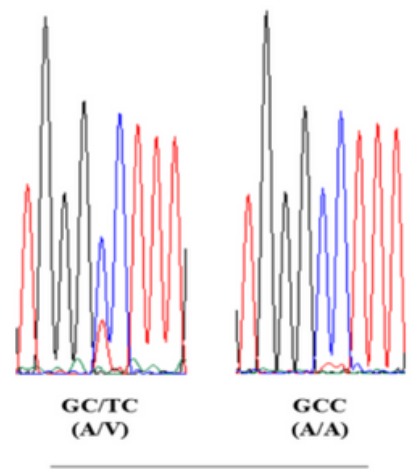

Locus 342

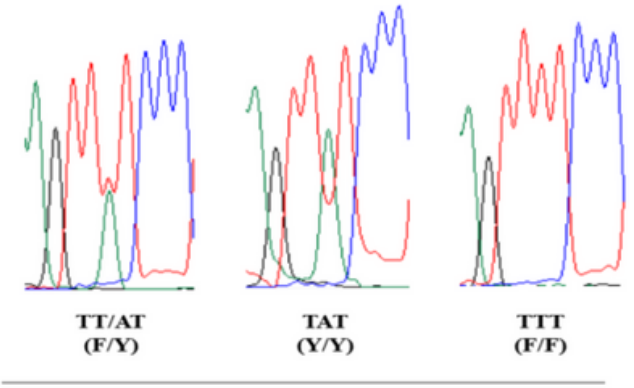

Locus 407

Figure 2

Chromatograms of eight ace genotypes detected at locus 260, 342 and 407 in Musca domestica from Guizhou province. AFLVY in brackets are abbreviations for alanine, phenylalanine, leucine, valine and tyrosine respectively.
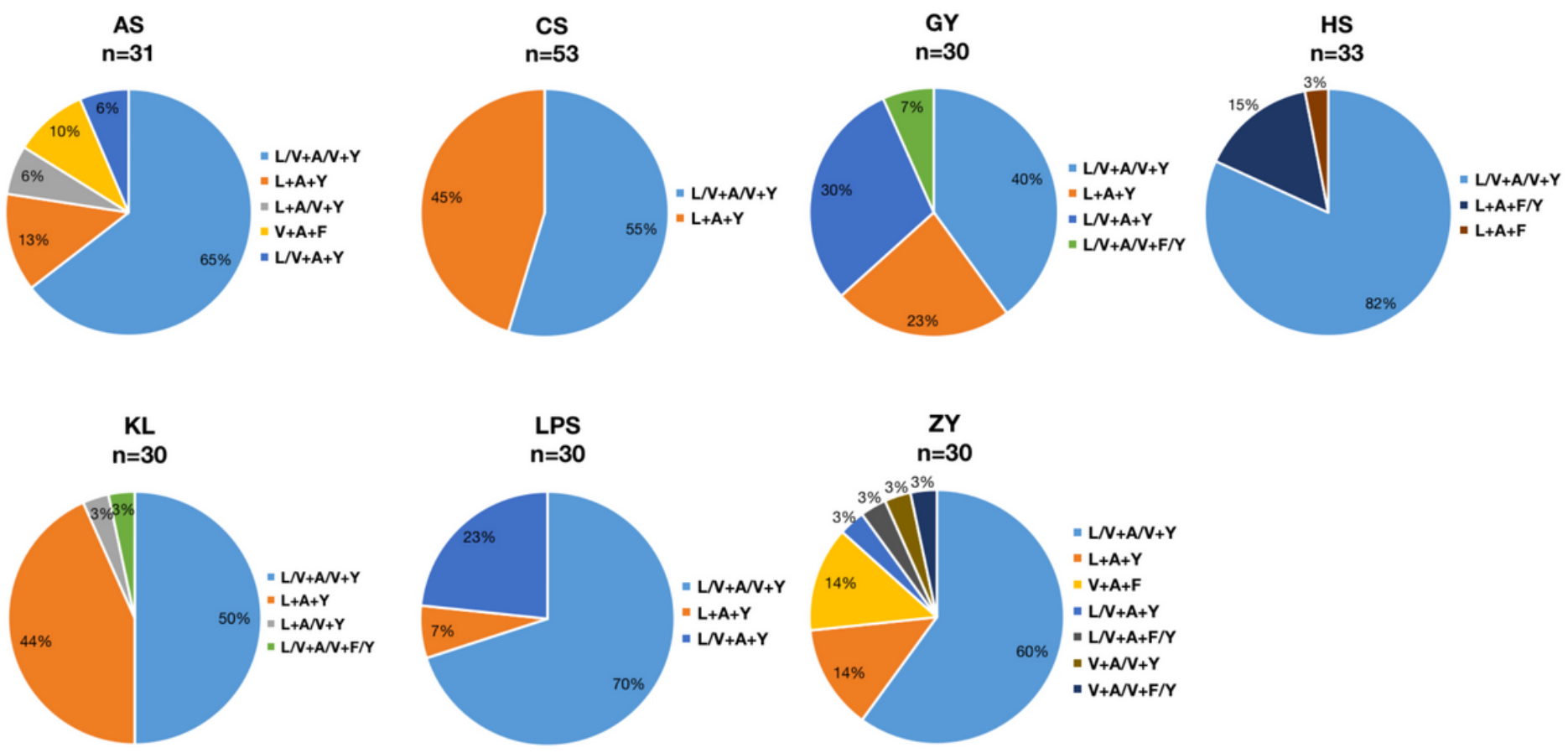

Figure 3 
The percentage of 10 ace mutation combinations at loci 260, 342 and 407 in 7 housefly populations. The predominant amino acid substitution type was $\mathrm{L} / \mathrm{V}+\mathrm{A} / \mathrm{V}+\mathrm{Y}$ (blue), followed by L+A+Y (orange).
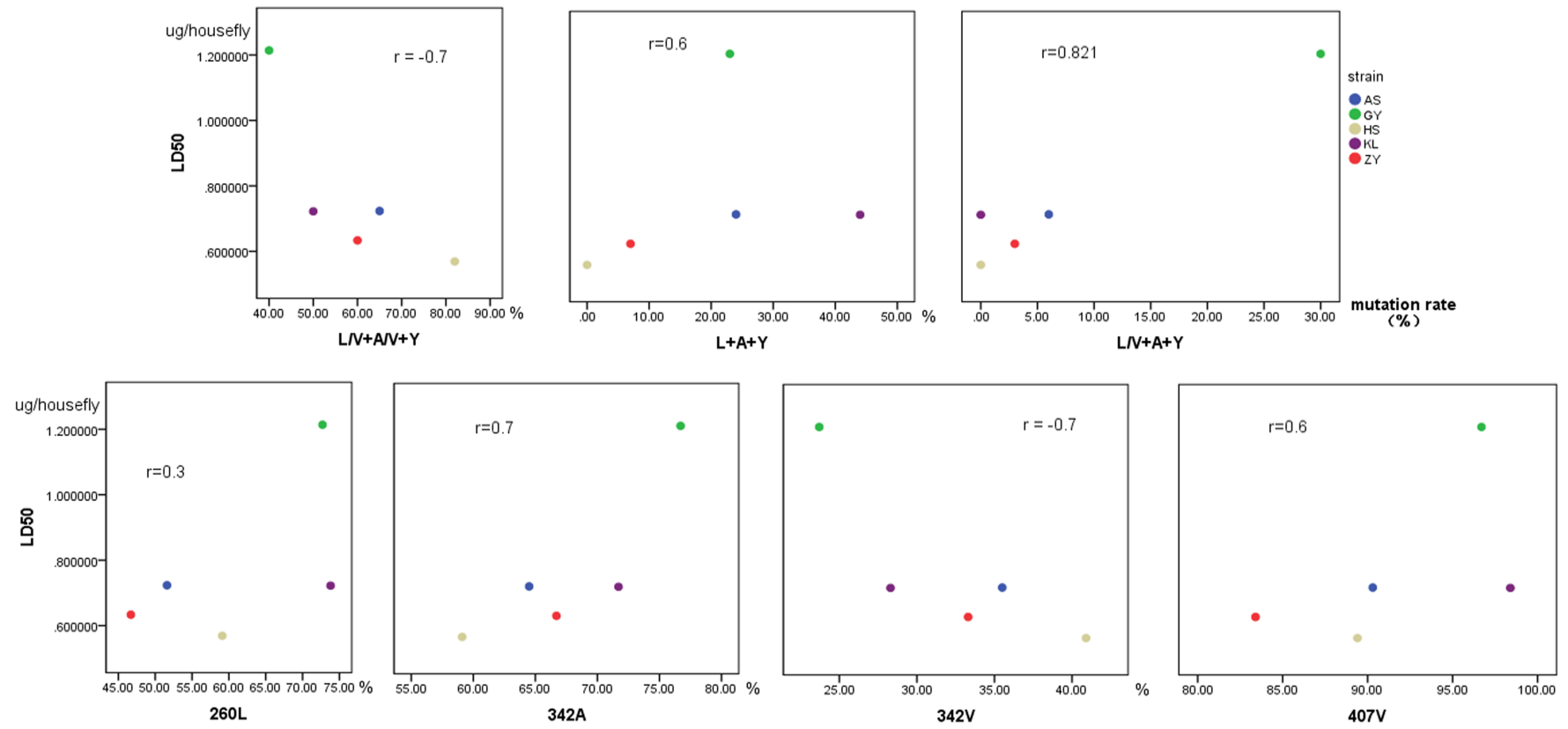

$(\%)$ rate

Figure 4

The correlation between single mutation/ combined mutations of ace gene and DDVP resistance to field populations of the housefly in Guizhou province.

\section{Supplementary Files}

This is a list of supplementary files associated with this preprint. Click to download.

- fig.S1.docx 